\title{
PENGARUH PENDEKATAN IMPLEMENTATION INTENTION DALAM MANAJEMEN PERAWATAN DIRI PADA PASIEN DIABETES MELLITUS TIPE 2
}

\author{
Dewi Purnama Sari ${ }^{1)}$, Kusnanto ${ }^{2)}$, Esti Yunitasari ${ }^{2)}$ \\ 1) Magister Keperawatan Fakultas Keperawatan, Universitas Airlangga \\ Email: dedewi84@gmail.com \\ 2) Fakultas Keperawatan, Universitas Airlangga
}

\begin{abstract}
Education about self-care DM type 2 has been given, but the failure rate in achieving glycemic control is still high. This leads to the risk of Diabetes Mellitus complications referring to the high cost of care. Action of self-care management of patients with type 2 diabetes is based on the intention. However, intention can not always be an action because of the barrier of self-control (self regulatory problem). Implementation intention becomes an effort in improving the realization of intention into action. This study aims to analyze the influence of implementation intention approach in the self-care management of type 2 Diabetes Mellitus patients. This study uses the quasy experiment method (pre-post test with control design) with comparing the effect of implementation intention in 2 group. The study was conducted in Internal Medicine Outpatient Ward in University of Airlangga Hospital with a total sample of 38 people with hypothesis test formula data proportion of two populations 1 tailed. Variable include action of nutrition management, modification of physical activity, medication adherence and self monitoring blood glucose measures using a questionnaire instrument. Data were analyzed through independent $t$-test. The result of the research shows that $\mathrm{p}$ value $<$ tolerance level with $\alpha=0,05$ means that Ho is rejected, so there is an influence between implementation intention approach with nutrition management, modification of physical activity, and medication compliance. Whereas if obtained $\mathrm{p}$ value $>$ tolerance level means Ho accepted, so there is no effect of implementation implementation approach with self monitoring of blood glucose. Conclusions: the impelementation intention approach improves the application of self-care management in nutrition management, modification of activity and medication adherence but can not improve action in independent self monitoring blood glucose (SMBG). Reccomendation: Further research can develop SMBG variables by providing standardized assessment based on patient needs and situations; allowing more than 4 weeks, grouping respondents homogeneously based on individual characteristics.
\end{abstract}

Key word: Diabetes mellitus tipe 2, implementation intention, management of self care

\begin{abstract}
Abstrak: Edukasi telah diberikan pada pasien DM tipe 2 namun sebagian besar pasien belum dapat mencapai kontrol glukosa darah yang baik. Hal ini menyebabkan komplikasi yang mengarah pada peningkatan biaya perawatan kesehatan. Tindakan dalam manajemen perawatan diri DM tipe 2 berdasarkan niat. Akan tetapi niat tidak selalu menjadi tindakan dikarenakan hambatan pengendalian diri. Implementation intention menjadi upaya penting dalam meningkatkan perwujudan niat menjadi tindakan. Penelitian ini bertujuan menganalisis peningkatan tindakan dalam manajemen perawatan diri setelah diberikan pendekatan implementation intention. Desain penelitian adalah quasy experiment (pre-post test with control design). Lokasi penelitian di Poli Penyakit Dalam RS. UNAIR Surabaya dengan besar sampel total 38 orang. Pengukuran variabel yang terdiri dari manajemen nutrisi, modifikasi aktifitas fisik dan kepatuhan pengobatan menggunakan instrumen kuesioner, sedangkan pemantauan glukosa darah mandiri menggunakan instrumen lembar
\end{abstract}


catatan harian. Analisis data menggunakan independent t-test. Hasil penelitian menunjukkan bahwa nilai $\mathrm{p}<\alpha=0,05(\mathrm{p}=0,023 ; 0,003 ; 0,000)$ berarti ada peningkatan tindakan dalam manajemen nutrisi, modifikasi aktifitas fisik dan kepatuhan pengobatan setelah diberikan pendekatan implementation intention. Sedangkan pada variabel pamantauan glukosa darah didapatkan nilai $\mathrm{p}>\alpha=0,05(\mathrm{p}=0,953)$ berarti tidak ada peningkatan tindakan dalam pemantauan glukosa darah mandiri setelah diberikan pendekatan implementation intention. Kesimpulan pendekatan impelementation intention meningkatkan penerapan manajemen perawatan diri dalam manajemen nutrisi, modifikasi aktifitas dan kepatuhan pengobatan namun tidak dapat meningkatkan tindakan dalam pemantauan glukosa darah mandiri (PGDM). Saran penelitian selanjutnya dapat mengembangkan variabel PGDM dengan memberikan standart penilaian berdasarkan kebutuhan dan situasi pasien, memberikan waktu lebih dari 4 minggu, mengelompokkan responden secara homogen berdasarkan karakteristik individu.

Kata Kunci: Diabetes mellitus tipe 2, implementation intention, manajemen perawatan Diri

\section{PENDAHULUAN}

Edukasi tentang perawatan DM tipe 2 telah diberikan oleh tenaga kesehatan pada pasien DM tipe 2, namun sebagian besar pasien belum dapat mencapai kontrol glukosa darah yang baik. Manajemen perawatan yang buruk akan berpengaruh pada kondisi glikemik yang buruk mengarah pada komplikasi diabetikum. Perlu adanya pendekatan implementation intention dalam edukasi tentang manajemen perawatan diri pada pasien. Implementation intention adalah strategi powerfull self regulatory yang berupa perencanaan terkait waktu, tempat dan cara (Gollwitzer, \&Brandsatter, 1997). Penelitian ini berfokus pada peningkatan tindakan dalam manajemen perawatan diri yang terdiri dari manajemen nutrisi, modifikasi aktifitas fisik, kepatuhan pengobatan dan pemantauan glukosa darah mandiri.

\section{METODE PENELITIAN}

Penelitian ini menggunakan desain quasi eksperimental. Populasi dalam penelitian ini yaitu seluruh pasien rawat jalan di RS. UNAIR. Teknik sampling yang digunakan adalah consecutive Tabel 1. Data Penerapan Manajemen Nutrisi sebelum dan sesudah Pendekatan Implementation Intention

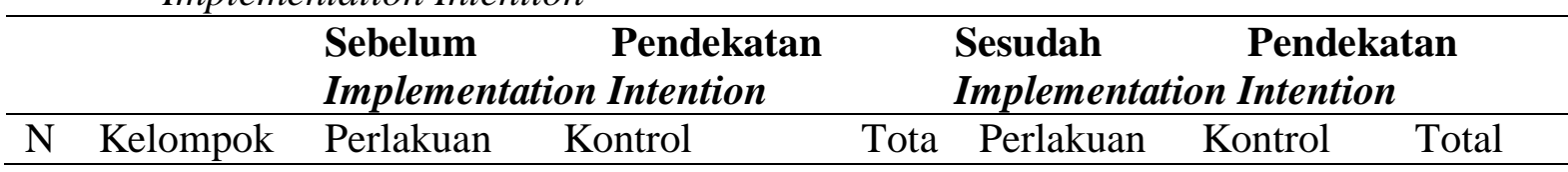

sampling didapatkan besar sampel 38 orang dengan penghitungan rumus uji hipotesa data proporsi dua populasi 1 tailed. Pengumpulan data menggunakan instrumen kuesioner dan lembar catatan harian. Variabel penelitian ini terdiri dari variabel independent yaitu pendekatan implementation intention dan variabel dependent yaitu manajemen nutrisi, modifikasi aktifitas fisik, kepatuhan pengobatan dan pemantauan glukosa darah mandiri. Data karakteristik individu dianallisis secara univariat. Data kemudian dianalisis secara bivariat menggunakan independent $t$ test dengan uji normalitas dan homogenitas sebelumnya untuk melihat distribusi data.

\section{HASIL \& PEMBAHASAN \\ Hasil}

Hasil penelitian menjelaskan uji statistik uji independent $\mathrm{t}$ digunakan untuk mengetahuii perbedaan rata-rata kelompok kontrol dan perlakuaan setelah pendekatan implementation intention.

A. Penerapan Manajemen Perawatan Diri Sebelum dan Sesudah Pendekatan Implementation Intention 


\begin{tabular}{llllllllllll}
\hline o. & & $(\mathrm{K} 1)$ & & $(\mathrm{K} 0)$ & & $\mathrm{l}$ & $(\mathrm{K} 1)$ & & $(\mathrm{K} 0)$ & & \\
\hline & $\begin{array}{l}\text { Kategori } \\
\text { Tindakan }\end{array}$ & $\mathrm{n}$ & $\%$ & $\mathrm{n}$ & $\%$ & $\mathrm{n}$ & $\mathrm{n}$ & $\%$ & $\mathrm{n}$ & $\%$ & \\
\hline 1 & Baik & 15 & 78,9 & 13 & 68,4 & 28 & 19 & 100 & 11 & 57,9 & 30 \\
\hline 2 & Cukup & 3 & 15,8 & 6 & 31,5 & 9 & 0 & 0 & 7 & 36,8 & 7 \\
\hline 3 & Kurang & 1 & 5,26 & 0 & 0 & 1 & 0 & 0 & 1 & 5,26 & 1 \\
\hline & Total & 19 & 100 & 19 & 100 & 38 & 19 & 100 & 19 & 100 & 38 \\
\hline & Mean & 75,9 & & 77,0 & & & 88,9 & & 84,4 & & \\
\hline & Median & 80,0 & & 80,0 & & & 86,6 & & 83,3 & & \\
\hline & St. Dev & 10,8 & & 7,2 & & & 5,7 & & 6,90 & & \\
\hline
\end{tabular}

Tindakan reponden dalam manajemen nutrisi sebelum pendekatan implementation intention pada kelompok perlakuan sebagian besar baik yaitu 15 orang responden $(78,94 \%)$, sedangkan pada kelompok kontrol sebagian besar baik yaitu 13 orang responden $(68,42 \%)$. Rata-rata nilai tindakan pada kelompok kontrol $(77,02)$ lebih baik dibandingkan kelompok perlakuan $(75,96)$.
Tindakan reponden dalam manajemen nutrisi sesudah pendekatan implementation intention pada kelompok perlakuan seluruhnya menjadi baik yaitu 19 orang responden (100\%), sedangkan pada kelompok kontrol sebagian besar baik yaitu 11 orang responden $(57,90 \%)$. Rata-rata nilai tindakan pada kelompok perlakuan $(88,95)$ lebih baik dibandingkan kelompok kontrol

$(84,04)$.

Tabel 2. Data tentang Penerapan Modifikasi Aktifitas Fisik sebelum dan sesudah Pendekatan Implementation Intention

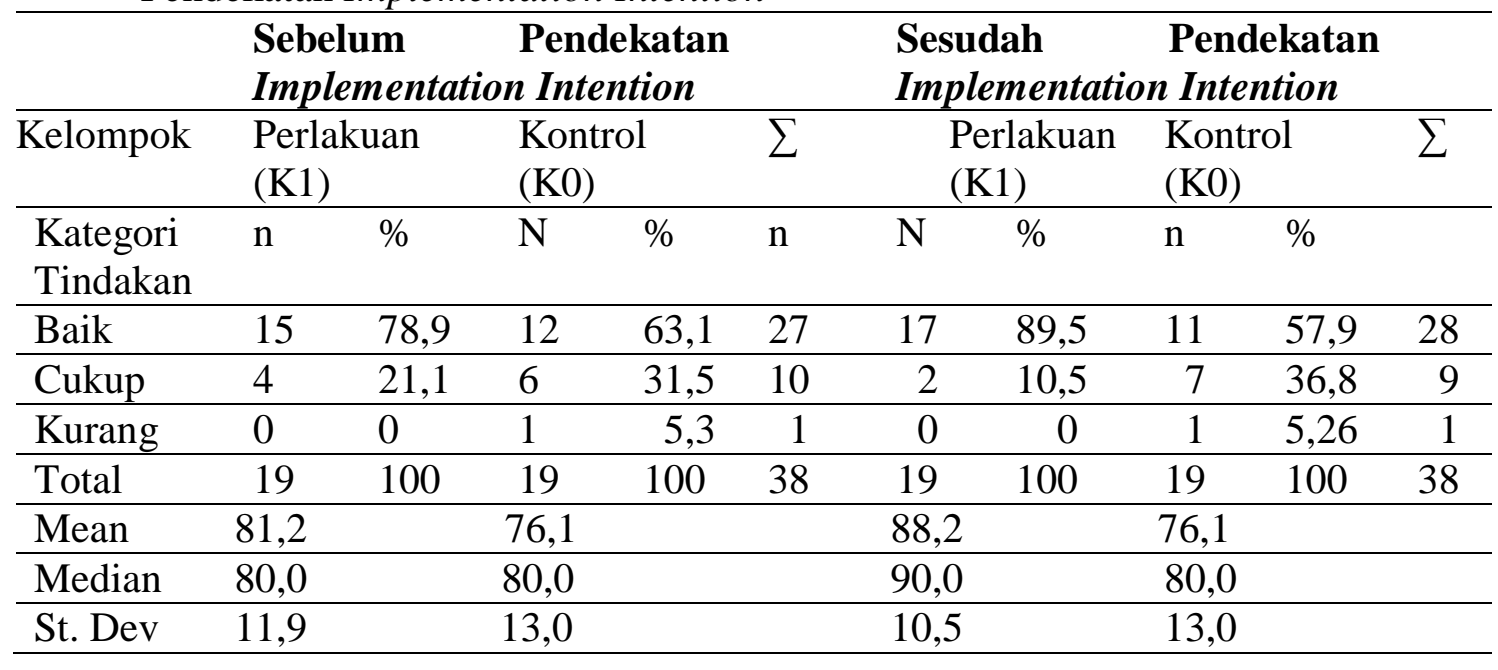

Tindakan reponden dalam modifikasi aktifitas fisik sebelum pendekatan implementation intention pada kelompok perlakuan sebagian besar baik yaitu 15 orang responden $(78,94 \%)$, sedangkan pada kelompok kontrol sebagian besar baik yaitu 12 orang responden $(63,16 \%)$. Rata-rata nilai tindakan pada kelompok perlakuan $(81,23)$ lebih baik dibandingkan kelompok kontrol $(76,14)$.
Tindakan responden dalam modifikasi aktifitas fisik sesudah pendekatan implementation intention pada kelompok perlakuan sebagian besar baik yaitu 17 orang responden $(89,47 \%)$, sedangkan pada kelompok kontrol sebagian besar baik yaitu 11 orang responden $(57,90 \%)$. Rata-rata nilai tindakan pada kelompok perlakuan $(88,25)$ lebih baik dibandingkan kelompok kontrol

$(76,14)$. 
3. Data tentang Penerapan Kepatuhan Pengobatan sebelum dan sesudah Pendekatan Implementation Intention

\begin{tabular}{|c|c|c|c|c|c|c|c|c|c|c|}
\hline \multirow{3}{*}{$\begin{array}{l}\text { Kelompok } \\
\text { Kategori } \\
\text { Tindakan }\end{array}$} & \multicolumn{4}{|c|}{$\begin{array}{l}\text { Sebelum Pendekatan } \\
\text { Implementation Intention }\end{array}$} & & \multicolumn{4}{|c|}{$\begin{array}{l}\text { Sesudah Pendekatan } \\
\text { Implementation Intention }\end{array}$} & \\
\hline & \multicolumn{2}{|c|}{$\begin{array}{l}\text { Perlakuan } \\
\text { (K1) }\end{array}$} & \multicolumn{2}{|c|}{$\begin{array}{l}\text { Kontrol } \\
\text { (K0) }\end{array}$} & \multirow[t]{2}{*}{$\sum$} & \multicolumn{2}{|c|}{$\begin{array}{l}\text { Perlakuan } \\
\text { (K1) }\end{array}$} & \multicolumn{2}{|c|}{$\begin{array}{l}\text { Kontrol } \\
\text { (K0) }\end{array}$} & \\
\hline & $\mathrm{n}$ & $\%$ & $\mathrm{~N}$ & $\%$ & & $\mathrm{n}$ & $\%$ & $\mathrm{n}$ & $\%$ & \\
\hline Baik & 6 & 31,6 & 8 & 42,1 & 14 & 19 & 100 & 8 & 42,1 & 27 \\
\hline Cukup & 9 & 47,4 & 11 & 57,9 & 20 & 0 & 0 & 11 & 57,9 & 11 \\
\hline Kurang & 4 & 21,0 & 0 & 0 & 4 & 0 & 0 & 0 & 0 & 0 \\
\hline Total & 19 & 100 & 19 & 100 & 38 & 19 & 100 & 19 & 100 & 38 \\
\hline Mean & 64,7 & & 77,3 & & & 91,2 & & 70,3 & & \\
\hline Median & 66,6 & & 70,0 & & & 93,3 & & 70,0 & & \\
\hline St. Dev & 13,3 & & 10,1 & & & 5,9 & & 10 & & \\
\hline
\end{tabular}

Tindakan reponden dalam kepatuhan pengobatan sebelum pendekatan implementation intention pada kelompok perlakuan sebagian besar cukup yaitu 9 orang responden $(47,37 \%)$, sedangkan pada kelompok kontrol sebagian besar cukup yaitu 11 orang responden $(57,89 \%)$. Rata-rata nilai tindakan pada kelompok kontrol $(70,35)$ lebih baik dibandingkan kelompok perlakuan $(64,74)$.
Tindakan reponden dalam kepatuhan pengobatan sesudah pendekatan implementation intention pada kelompok perlakuan sebagian besar baik yaitu 19 orang responden (100\%), sedangkan pada kelompok kontrol sebagian besar cukup yaitu 8 orang responden $(42,10 \%)$. Ratarata nilai tindakan pada kelompok perlakuan $(91,93)$ lebih baik dibandingkan kelompok kontrol $(70,35)$.

Tabel 4. Data tentang Penerapan Pemantauan Glukosa Darah sebelum dan sesudah Pendekatan Implementation Intention

\begin{tabular}{|c|c|c|c|c|c|c|c|c|c|c|}
\hline \multirow{3}{*}{$\begin{array}{l}\text { Kelompok } \\
\text { Kategori } \\
\text { Tindakan } \\
\end{array}$} & \multirow{2}{*}{\multicolumn{2}{|c|}{$\begin{array}{l}\begin{array}{l}\text { Sebelum } \\
\text { Implementa }\end{array} \\
\begin{array}{l}\text { Perlakuan } \\
(\mathrm{K} 1)\end{array} \\
\end{array}$}} & \multicolumn{3}{|c|}{$\begin{array}{l}\text { Pendekatan } \\
\text { on Intention }\end{array}$} & \multirow{2}{*}{\multicolumn{3}{|c|}{$\begin{array}{l}\text { Sesudah } \\
\text { Implementation } \\
\text { Perlakuan }\end{array}$}} & \multicolumn{2}{|c|}{$\begin{array}{l}\text { Pendekatan } \\
\text { ntention }\end{array}$} \\
\hline & & & $\begin{array}{l}\text { Kor } \\
\text { (K0 }\end{array}$ & & $\sum$ & & & & $\begin{array}{l}\text { Kontrol } \\
(\mathrm{K} 0)\end{array}$ & $\sum$ \\
\hline & $\mathrm{n}$ & $\%$ & $\mathrm{n}$ & $\%$ & $\mathrm{n}$ & $\mathrm{n}$ & $\%$ & & $\%$ & \\
\hline Baik & 0 & 0 & 0 & 0 & 0 & 2 & 10,5 & 0 & 0 & 2 \\
\hline Cukup & 7 & 36,8 & 7 & 36,8 & 14 & 7 & 36,8 & 8 & 42,1 & 15 \\
\hline Kurang & 12 & 63,2 & $' 12$ & 63,2 & 24 & 10 & 52,7 & 11 & 57,9 & 21 \\
\hline Total & 19 & 100 & 19 & 100 & 38 & 19 & 100 & 19 & 100 & 38 \\
\hline Mean & 48,3 & & 47,9 & & & 51,2 & & & 1,0 & \\
\hline Median & 45,2 & & 47,6 & & & 50,0 & & & 0,0 & \\
\hline St. Dev & 8,6 & & 9,8 & & & 11,5 & & 4,3 & & \\
\hline
\end{tabular}

Tindakan responden dalam pemantauan glukosa darah mandiri sebelum pendekatan implementation intention pada kelompok perlakuan sebagian besar kurang yaitu 12 orang responden $(63,16 \%)$, sedangkan pada kelompok kontrol sebagian besar kurang yaitu 12 orang responden $(63,16 \%)$. Sehingga dapat disimpulkan bahwa tindakan dalam pemantauan glukosa darah mandiri sebelum pendekatan implementation intention tergolong 
kurang pada kedua kelompok yaitu sebanyak 24 orang responden $(63,16 \%)$. Rata-rata nilai tindakan pada kelompok kontrol $(48,37)$ sama-sama kurang dengan kelompok perlakuan $(47,99)$.

Tindakan reponden dalam pemantauan glukosa darah mandiri sesudah pendekatan implementation intention pada kelompok perlakuan sebagian besar kurang yaitu 10 orang responden $(52,63 \%)$, sedangkan pada kelompok kontrol sebagian besar kurang yaitu 11 orang responden $(57,89 \%)$. Sehingga dapat disimpulkan bahwa tindakan dalam pemantauan glukosa darah mandiri setelah pendekatan implementation intention tergolong kurang pada kedua kelompok yaitu sebanyak 21 orang responden $(55,27 \%)$. Rata-rata nilai tindakan pada kelompok kontrol (51,00) sama-sama cukup dibandingkan kelompok perlakuan $(51,25)$.

B. Uji Statistik Bivariat Beda Rata-rata Pre dan Post Test

Tabel 5. Rekapitulasi Hasil Analisis Uji t Post Test

\begin{tabular}{|c|c|c|c|}
\hline Variabel & $\mathbf{t}_{\text {hitung }}$ & Sig. t & Keterangan \\
\hline $\begin{array}{c}\text { Manajemen Nutrisi Post } \\
\text { Test }\end{array}$ & 2,379 & 0,023 & $\begin{array}{c}\text { Berbeda } \\
\text { Signifikan }\end{array}$ \\
\hline $\begin{array}{c}\text { Modifikasi Aktifitas Fisik } \\
\text { Post Test }\end{array}$ & 3,155 & 0,003 & $\begin{array}{c}\text { Berbeda } \\
\text { Signifikan }\end{array}$ \\
\hline $\begin{array}{c}\text { Kepatuhan Pengobatan } \\
\text { Post Test }\end{array}$ & 7,992 & 0,000 & $\begin{array}{c}\text { Berbeda } \\
\text { Signifikan }\end{array}$ \\
\hline $\begin{array}{c}\text { Pemantauan Glukosa } \\
\text { Darah Mandiri Post test }\end{array}$ & 0,059 & 0,953 & $\begin{array}{c}\text { Tidak Berbeda } \\
\text { Signifikan }\end{array}$ \\
\hline
\end{tabular}

Dari tabel di atas pada masingmasing variabel dalam penerapan manajemen perawatan diri pasien DM tipe 2 terlihat nilai signifikansi (Sig.) pada masing-masing variabel $t$ kurang dari 0,05 (sig.t < 0,05) menunjukkan bahwa $\mathrm{H} 1$ diterima artinya bahwa kedua rata-rata populasi post test kelompok perlakuan dan kontrol adalah berbeda secara signifikan, kecuali variabel pemantauan glukosa darah mandiri.

Pada variabel manajemen nutrisi, $p$ hitung $=0,023 \quad(\alpha<0,05)$ sehingga $\mathrm{H} 1$ diterima artinya bahwa pendekatan implementation intention meningkatkan penerapan tindakan dalam manajemen nutrisi. Pada variabel modifikasi aktifitas fisik, $\mathrm{p}$ hitung $=0,003 \quad(\alpha<0,05)$ sehingga H1 diterima artinya bahwa pendekatan implementation intention meningkatkan penerapan tindakan dalam modifikasi aktifitas fisik. Pada variabel kepatuhan pengobatan, $p$ hitung $=0,000 \quad(\alpha<0,05)$ sehingga $\mathrm{H} 1$ diterima artinya bahwa pendekatan implementation intention meningkatkan penerapan tindakan dalam kepatuhan pengobatan. Pada variabel pemantauan glukosa darah mandiri, $p$ hitung $=0,953 \quad(\alpha>0,05) \quad$ sehingga $\mathrm{H} 1$ ditolak artinya bahwa pendekatan implementation intention tidak meningkatkan penerapan tindakan dalam pemantauan glukosa darah mandiri.

\section{Pembahasan}

Pokok pembahasan hasil penelitian menjelaskan variabel dalam manajemen perawatan diri pada pasien Diabetes Mellitus yang meliputi manajemen nutrisi, modifikasi aktifitas fisik dan pemantauan glukosa darah mandiri.

1. Manajemen nutrisi

Pendekatan implementation intention dalam edukasi meningkatkan tindakan dalam manajemen nutrisi. Tindakan responden dalam manajemen nutrisi terdiri dari pemilihan jenis, waktu, tempat dan cara dalam mengelola, menyajikan dan menyantap makanan yang sesuai dengan anjuran pedoman pencegahan dan 
pengendalian DM tipe 2 (PERKENI, 2015).

Perubahan pola diit membutuhkan pengendalian kognitif (Luszczunska, Scholz\&Sutton, 2007). Dalam perawatan DM tipe 2 sangat diperlukan perilaku diit untuk mencapai kontrol glikemik yang stabil. Perubahan tahapan perilaku melalui proses precontemplation (sebelum berfikir), contemplation (berpikir), preparation (persiapan), action (tindakan) dan manintenance (pemeliharaan) yang sesuai pada pengelolaan diit tersebut berdasarkan model transtheoretical (TTM) (Armitage, 2006). Hasil penelitian menyebutkan bahwa sebagian besar orang berpindah dari satu tahapan ke tahapan selanjutnya menggunakan implementation intention (Nadkarni, 2009).

Edukasi yang diberikan dengan pendekatan implementation intention dalam bentuk individual brainstorming. Peneliti dan responden membuat perencanaan berisi penyelesaian masalah dengan format "jika saya memenuhi situasi Y, maka saya akan melakukan $\mathrm{Z}$ agar tindakan $\mathrm{X}$ dapat terwujud". Responden perlu megingat yang diungkapkan. "jika saya sedang (waktu) panen buah mangga di rumah (tempat) (Y), maka saya akan makan secukupnya, tidak sembunyi-sembunyi (Z) (cara) agar saya bisa mengurangi konsumsi tinggi gula (X)". Penelitian sebelumnya memiliki metode yang sama yaitu dengan menggolongkan secara spesifik perencanaan responden terkait tempat, waktu dan cara (Verhoeven, Adriaanse dkk, 2013).

\section{Modifikasi aktifitas fisik}

Pendekatan implementation intention dalam edukasi meningkatkan tindakan dalam manajemen nutrisi. Ada penjelasan bahwa terdapat hubungan yang kuat antara tingkat aktifitas olahraga yang ringan-sedang-berat dengan masalah kesehatan yang dimiliki oleh pasien (Departemen Kesehatan-WHO, 2004 dalam Hagger, 2010). Pasien Diabetes mellitus tipe 2 pada kelompok perlakuan mampu memiliki pengendalian diri dalam mempertahankan dan meningkatkan aktifitas harian yang rutin baik secara mandiri maupun bersama-sama. Sebagian besar data pasien menyebutkan bahwa pasien memiliki pola intensitas aktifitas dan olahraga yang sedang ditandai dengan usaha nafas terengah-engah, mampu berbicara, dan sudah tidak mampu bernyanyi. Pasien memiliki kategori durasi yang baik yaitu 30-60 menit dan frekuensi 3-5 kali dalam seminggu. Jenis olahraga yang dianjurkan seperti jalan kaki merupakan pilihan tepat yang telah dijalani oleh responden. Sedangkan pada kelompok kontrol, responden sebagian besar memiliki kategori aktifitas fisik dengan intensitas ringan, durasi 30-60 menit dan frekuensi1-2 kali dalam seminggu.

Pendekatan implementation
intention merupakan upaya dalam
mengatasi kendala dan situasi masingmasing individu. "Jika saya lupa melakukan aktifitas jalan pagi(situasi Y), maka saya akan mengganti jadwal dengan jalan (Z) pada sore hari (waktu) di sekitar rumah selama 60 menit (durasi waktu), 3 kali dalam seminggu (frekuensi) untuk mempertahankan pola aktifitas olahraga saya (X)". Lupa merupakan kendala yang sering ditemukan. Namun penelitian ini sejalan dengan penemuan sebelumnya bahwa implementation intention meningkatkan respon yang efektif terhadap situasi lupa (Gollwitzer\&Sheeran, 2005).

3. Kepatuhan pengobatan

Pendekatan implementation intention dalam edukasi meningkatkan tindakan dalam kepatuhan pengobatan. Pasien dan peneliti mengadakan komunikasi secara efektif melalui individual brainstorming tentang hal-hal apa saja yang menjadi pertanyaan dan dapat mendorong tercapaianya keberhasilan pengobatan. Pasien membuat suatu pernyataan implementation intention yang berupa perencanaan terkait waktu, tempat dan cara agar terwujud pemberian obat baik 
yang diberikan secara oral maupun insulin. Pada kelompok perlakuan, pasien mampu menerapkan perencanaan dengan memperhatikan cara dalam implementation intention.

Pendekatan implementation intention menyebabkan seseorang menyiapkan situasi tertentu misalnya "jika pukul 07.00 (waktu) dan saya selesai minum obat (situasi $\mathrm{Y}$ ) maka saya akan menyimpan sisa obat (Z) untuk saya minum siang dan sore hari (X) pada tempat kotak kecil (tempat) yang sudah saya tandai dan letakkan kembali di tempat khusus (di lemari plastik) (cara)", atau "jika pagi hari (waktu) saya bangun tidur (situasi Y) saya menggantungkan insulin di atas tempat tidur saya (cara dan tempat) setelah saya menyuntik insulin pertama pagi hari $(\mathrm{Z})$ agar saya tidak lupa untuk menyuntikkan insulin setiap pagi"(X). Implementation intention meningkatkan kemungkinan isyarat lingkungan mendapatkan respon yang diinginkan sehingga sebuah tindakan dapat terwujud (Sheeran, 2002).

4. Pemantauan glukosa darah mandiri

Pendekatan implementation intention dalam edukasi tidak mampu meningkatkan tindakan dalam pemantauan glukosa darah mandiri. Edukasi pada pemantauan glukosa darah mandiri memiliki tujuan mendorong partisipasi aktif dan efektif seorang penderita DM tipe 2 dalam kontrol, memberi adaptasi tentang manajemen glukosa darah sehari-hari, memberi instruksi keterampilan penanganan komplikasi akut yang terjadi seperti hipoglikemia, memberi keyakinan untuk melakukan perubahan perilaku dan gaya hidup (PERKENI, 2015). Pemantauan glukosa darah mandiri memerlukan unsur keyakinan akan keberhasilan dalam mencapai target kontrol glikemik. Pendekatan implementation intention berfous pada tujuan pemantauan glukosa darah mandiri. Sehingga landasan berpikir dan motivasi pasien mendorong rutinitas pemantauan glukosa darah secara mandiri (Mulligan, 2017).
Pada sebagian besar responden $(80 \%)$, kondisi penglihatan yang dimiliki sudah berkurang menyebabkan tindakan pemantauan glukosa darah tidak dapat dikerjakan tanpa bantuan dari anggota keluarga yang lain. Dukungan keluarga sangat diperlukan. Pendekatan implementation intention pada penelitian ini menggunakan edukasi dan lembar catatan harian. Penelitian sebelumnya menemukan bahwa implementation intention signifikan mempengaruhi tindakan pemantauan glukosa darah melalui recalling (mengingatkan kembali). Hal ini sesuai dengan prinsip yang sudah dijelaskan pada teori sebelumnya bahwa perencanaan tempat, waktu dan cara dalam dihambat oleh kegagalan saat memulai diantaranya faktor mengingat kembali dan mengambil kesempatan saat melakukan (Golwitzer\&Sheeran, 2006). Dengan mengingatkan kembali, pasien dan keluarga dapat meningkatkan respon yang dibutuhkan untuk mempertahankan pemantauan glukosa darah mandiri.

\section{SIMPULAN}

Pendekatan implementation intention tidak meningkatkan tindakan pemantauan glukosa darah mandiri dalam manajemen perawatan diri pada pasien DM tipe 2

\section{DAFTAR PUSTAKA}

Armitage CJ, 2006, Evidence that Implementation Intentions Promote Transitions between stages of changes. Journal of consulting and clinical psychology, 74(1):141-151

Hagger, Martin S; Wood, Chantelle W.; Stiff, Chris, 2010, Self- regulation and self control in exercise: the strength-energy model, dipublikasikan International Review of Sport

Gollwitzer\&Branstatter ,1997,Implementa tion Intention and Effective Goal Pursuit, journal of personality and social psychology 1997 vol 73 no 185-199 
http://www.psych.nyu.edu/gollwitze r/97GollBrand_ImpIntGoalPurs.pdf Gollwitzer\&Sheeran, 2005, The Interplay between Goal Intention and Implementation Intentionshttp://www.psych.nyu.edu /gollwitzer/05_Sheeran_Webb_Goll witzer_Goal_Intention_Implementat ion.pdf

Gollwitzer\&

Sheeran, 2006,Implementation intentions and goal achievement: A meta-analysis of effects and processes. Advances in Experimental Social Psychology, 38, 69-119.

Luszczynska, Aleksandra; Scholz, Urte; Sutton, Stephen. 2007, Planning to change diet: A controlled trial of an implementation intention training intervention to reduce saturated fat intake among patients after myocardial infarcion, dipulikasikan dalam journal of Psychosomatic Research, 63,491-497

Mulligan, Kathleen, McBain, Hiyley, Lamontagne, Godwin, Federique, Chap, 2017, Barriers and enables of type 2 Diabetes self management in people with severe mental illness, Original research paper, wileyonline library.com/journal/hex, Health expectations:1-11

Nadkarni, 2009. Implementation Intention and Self Monitoring Blood Glucose, diambil dari https://www.researchgate.net/publicat ion/30864508_Implementation_Plans _and_Self-

Monitoring_of_Blood_Glucose_in_D iabetics

Perkumpulan Endokrinologi Indonesia, 2015, Petunjuk Praktis Pengelolaan dan Pencegahan Diabetes mellitus tipe 2 di Indonesia (editor : $\mathrm{S}$. Soegondo, P. Soewondo, I. Subekti), PB. PERSI

Sheeran, 2002, Intention-behavioral relation: $a$ and empirical review, diambil dari https://www.researchgate.net/publicat ion/230821783_Intention-

Behavior_Relations_A_Conceptual_a nd_Empirical_Review

Verhoeven, Adriaanse.,de Ridder, de Vet, \&Fennis, 2013,Less is more: the effect of multiple implementation intentions targeting unhealthy snacking habits, European Journal of Social Psychology 43, 344-354 (2013) 